\title{
REVIEWS
}

\section{Tricyclic and Tetracyclic Antidepressants for the Prevention of Frequent Episodic or Chronic Tension-Type Headache in Adults: A Systematic Review and Meta-Analysis}

\author{
Jeffrey L. Jackson, MD, MPH' ${ }^{1,2}$, Josephine M. Mancuso, $P h D^{7}$, Sarah Nickoloff, $M D^{1,2}$, \\ Rebecca Bernstein, MD, MSc ${ }^{2}$, and Cynthia Kay, MD, MSc ${ }^{1,2}$
}

'Zablocki VA Medical Center, Milwaukee, WI, USA; ${ }^{2}$ Medical College of Wisconsin, Milwaukee, WI, USA.

\begin{abstract}
BACKGROUND: Tension-type headaches are a common source of pain and suffering. Our purpose was to assess the efficacy of tricyclic (TCA) and tetracyclic antidepressants in the prophylactic treatment of tension-type headache.
\end{abstract}

METHODS: We searched the Cochrane Central Register of Controlled Trials, MEDLINE, EMBASE, the ISI Web of Science, and clinical trial registries through 11 March 2017 for randomized controlled studies of TCA or tetracyclic antidepressants in the prevention of tensiontype headache in adults. Data were pooled using a random effects approach.

KEY RESULTS: Among 22 randomized controlled trials, eight included a placebo comparison and 19 compared at least two active treatments. Eight studies compared TCAs to placebo, four compared TCAs to selective serotonin reuptake inhibitors (SSRIs), and two trials compared TCAs to behavioral therapies. Two trials compared tetracyclics to placebo. Single trials compared TCAs to tetracyclics, buspirone, spinal manipulation, transcutaneous electrical stimulation, massage, and intra-oral orthotics. High-quality evidence suggests that TCAs were superior to placebo in reducing headache frequency (weighted mean differences (WMD): -4.8 headaches/ month, 95\% CI: -6.63 to -2.95 ) and number of analgesic medications consumed (WMD: -21.0 doses/month, 95\% CI: -38.2 to -3.8$)$. TCAs were more effective than SSRIs. Low-quality studies suggest that TCAs are superior to buspirone, but equivalent to behavioral therapy, spinal manipulation, intra-oral orthotics, and massage. Tetracyclics were no better than placebo for chronic tension-type headache.

CONCLUSIONS: Tricyclic antidepressants are modestly effective in reducing chronic tension-type headache and are superior to buspirone. In limited studies, tetracyclics appear to be ineffective in the prophylactic treatment of chronic tension-type headache.

The views reflected in this manuscript are those of the authors and should not be construed, in any way, to represent the views of the Department of Veterans Affairs

Electronic supplementary material The online version of this article (doi:10.1007/s11606-017-4121-z) contains supplementary material, which is available to authorized users.

Received March 15, 2017

Revised April 27, 2017

Accepted June 12, 2017

Published online July 18, 2017
J Gen Intern Med 32(12):1351-8

DOI: $10.1007 / \mathrm{s} 11606-017-4121-\mathrm{Z}$

(c) Society of General Internal Medicine (outside the USA) 2017

\section{INTRODUCTION}

The two most common types of headache are tensiontype headache and migraine. Tension-type headache is more common, though migraines are generally more disabling and consequently have received greater attention. ${ }^{1}$ Up to $90 \%$ of adults will experience a tensiontype headache at some time in their lives, ${ }^{1-5}$ with $46 \%$ of adults experiencing tension-type headaches in any given month. ${ }^{1}$ Tension-type headache reduces the health-related quality of life, ${ }^{6}$ accounts for a significant number of work absences, ${ }^{7,8}$ and is expensive, costing $\$ 21$ billion annually, ${ }^{9}$ mostly in indirect costs, since the majority are successfully self-medicated with over-thecounter analgesics, and patients rarely seek medical attention. $^{8,10}$

Tension-type headache is typically bilateral, pressing or tightening in quality, and of mild to moderate intensity, lasting minutes to days. The pain does not worsen with routine physical activity and is not associated with nausea, though photophobia or phonophobia may be present. Tension-type headaches are subcategorized by frequency as infrequent episodic ( $<1$ headache/month, less than 12 times/year), frequent episodic (1-14 headaches/month), or chronic ( $>15$ headaches/ month $\left.{ }^{11}\right)$.

While numerous studies and reviews include recommendations regarding prophylactic management of migraine headaches, guidance for tension-type headache is less clear. ${ }^{12}$ Practice guidelines suggest a patient-centered approach when deciding whether to start prophylactic medications. ${ }^{13}$ Unfortunately, many patients who could benefit from prophylactic treatment are not receiving it. ${ }^{10}$ Busy clinicians face pressure to manage headache and evidence-based alternatives to opioids and barbiturates, which are not recommended, though commonly prescribed. ${ }^{14-16}$ Previous systematic reviews on tension-type headache have assessed the effectiveness of acupuncture, ${ }^{17}$ selective serotonin reuptake inhibitors (SSRIs) and serotonin-norepinephrine reuptake inhibitors, ${ }^{18}$ 
botulinum, ${ }^{19}$ and manual therapies. ${ }^{20}$ We previously published a systematic review evaluating tricyclics for tensiontype and migraine headaches, suggesting a benefit for both headache types. ${ }^{21}$ Systematic review methodology has become more rigorous since that publication, prompting us to update that review with more robust methods. The purpose of our present study was to assess the efficacy of tricyclic and tetracyclic antidepressants in the prophylactic management of tension-type headache in adults.

\section{METHODS}

\section{Data Sources and Searches}

We followed PRISMA guidelines. ${ }^{22}$ We searched the Cochrane Central Register of Controlled Clinical Trials, MEDLINE, EMBASE, ISI Web of Science (SCI, SSCI, CPCI-S, and CPCI-SSH) through 11 March 2017 (Online Table 1), with the help of a research librarian. We included English and non-English studies, manually reviewing bibliographies of retrieved studies.

\section{Study Selection}

We included randomized controlled studies of adults, at least four weeks in duration, and having at least one study arm with either a tricyclic or tetracyclic antidepressant for the prophylactic treatment of tension-type headache. An attempt was made to contact authors of studies without extractable data. Because the definition of headache has changed over time, and tension-type headache was poorly characterized before 1988, articles were reviewed by at least two authors to determine whether the headache could be reasonably classified as tension-type and as either frequent episodic or chronic according to the most recent International Classification of Headache Disorders. ${ }^{11}$

\section{Data Extraction and Quality Assessment}

We followed International Headache Society (IHS) recommendations by including only patient-reported outcomes and selecting headache frequency as our primary outcome. Secondary outcomes included the proportion of subjects with at least $50 \%$ improvement in symptoms, use of acute analgesic medications, headache index (typically a combination of frequency and severity), headache severity, headache duration, quality of life, study withdrawal, and adverse events. Abstraction and quality ratings were performed independently by at least two authors, with disagreements resolved through consensus.

We assessed bias using the Cochrane risk of bias instrument ${ }^{23}$ and the Jadad scale, ${ }^{24}$ independently, with good interrater reliability (intraclass correlation coefficient [ICC]: 0.82). Sample size was included as a quality marker, based on either individual study use of sample size calculations or our calculation that 60 subjects were required for continuous outcomes and 200 for dichotomous outcomes. ${ }^{12}$ Studies that did not measure or exclude depression were rated as potentially biased, since treating depression improves physical symptoms. ${ }^{25}$

\section{Data Synthesis and Analysis}

For crossover trials, we reduced the sample size by $50 \%{ }^{23}$ Headache frequency was pooled as headache days per month, headache duration as hours per month, and analgesic use as number of doses per month. Headache severity and headache index metrics were pooled using weighted mean differences (WMD) and standardized mean differences (SMD) ${ }^{26}$ Missing variances were imputed using standard methods. ${ }^{27}$ Heterogeneity was assessed using Cochran's Q, Galbraith plots, ${ }^{28}$ and the $\mathrm{I}^{2}$ statistic. ${ }^{29}$ We pooled data using a random effects model (STATA version 14.1; StataCorp LP, College Station TX). We determined a priori to pool data at $4,8,12,16,20$, and 24 weeks. For studies that reported outcomes at different time points, we combined them in the closest time point available. We assessed for publication bias when possible using the methods described by Peters ${ }^{30}$ for dichotomous outcomes and Egger $^{31}$ for continuous outcomes. In addition, we explored the potential impact of quality and heterogeneity on our outcomes using stratified analyses and meta-regression.

Finally, we assessed the quality of evidence using the GRADE (Grading of Recommendations Assessment, Development and Evaluation) system to rate the quality of the evidence (GRADEpro GDT 2015) following Cochrane guidelines. ${ }^{23,32}$ The GRADE system assigns ratings as follows: high (further research is unlikely to change estimate of effect), moderate (further research may impact estimate), low (further research is likely to change estimate), and very low (any estimate of effect is very uncertain).

\section{RESULTS}

Our search yielded 2195 unique studies. Application of inclusion and exclusion criteria (Online Figure 1) resulted in 31 randomized controlled trials. ${ }^{33-63}$ Ten of these were excluded: two reported non-randomized comparisons, ${ }^{40,60}$ another was stopped because of poor enrollment, ${ }^{61}$ another had no extractable data (and the authors did not respond to our attempts to contact them) ${ }^{57}$ three studies did not adequately specify the type of headache, ${ }^{37,39,53}$ and two focused on transformed migraine headaches ${ }^{41,50}$ and one on analgesic-induced chronic daily headaches. ${ }^{44}$ The 21 included studies ranged in size from 20 to 554 subjects (average: 131) and from 4 to 24 weeks in duration (average: 9.5 weeks). Participants in 15 studies met criteria for chronic tension-type headache. ${ }^{33-35,38,42,43,46-}$ $48,52,54,56,58,62,63$ The remaining studies included patients with both episodic and chronic tension-type headache, though the majority were chronic tension-type. ${ }^{45,49,51,55,59}$ All but one included only subjects 18 years and older. ${ }^{54}$ Eleven countries were represented. The average age was 37.9 years, and $71.5 \%$ of participants were women. Study characteristics for placebo- 
controlled trials are provided in Online Table 2 and comparative effectiveness trials in Online Table 3. Quality ratings of trials are given in Online Table 4.

Migraine is commonly comorbid among subjects suffering from tension-type headache. Five studies excluded participants with migraine headache, ${ }^{33,34,51,54,58}$ and four allowed participants to have both types of headache. ${ }^{45,55,59,62}$ The remaining trials did not mention migraine headache. Seven studies excluded patients with depression, ${ }^{33,35,38,46,47,54,58,63}$ eight studies measured depression, ${ }^{34,43,45,47,49,51,52,62}$ one focused on subjects with concomitant headaches and depression, ${ }^{59}$ and the remaining five had no information about depression. Studies also commonly had high dropout rates, averaging $13.8 \%$ (95\% CI: 0.08-19.6), most without an intention-to-treat analysis $(57 \%)$. Sixteen of the studies $(76 \%)$ were underpowered, and only three had samples based on power calculations.

\section{Placebo-Controlled Trials}

Eight double-blind randomized studies included a placebo arm. $^{33,34,45,46,49,51,55,58}$ Amitriptyline was the most common drug, used in six trials, ${ }^{33,45,46,49,51,55,58}$ with clomipramine ${ }^{51}$ and doxepin $^{55}$ studied in one trial each (Online Table 1). Tricyclic antidepressant (TCA) doses ranged from 10 to $150 \mathrm{mg}$. Among these trials, two measured depression, ${ }^{45,49}$ and three excluded subjects with depression. Tetracyclics were compared to placebo in two trials, one with mirtazapine ${ }^{34}$ and one with mianserin. ${ }^{51}$

\section{TCA versus Placebo}

Our primary outcome, headache frequency, was reported by five studies involving 387 participants (Fig. 1). At baseline, patients in both groups averaged 20.6 headaches per month (95\% CI: 20.4-20.8). Patients with chronic tension-type headache treated with amitriptyline had a reduction in headache frequency and headache index and increased health-related quality of life at all time points assessed. At 4 weeks, the amitriptyline group experienced 6.2 fewer headaches per month (95\% CI: -8.1 to -4.2 ; Fig. 1) than those receiving placebo. The findings were similar at 8 weeks $(-4.8$ headaches/month, $96 \%$ CI: -6.6 to -3.0$), 12$ weeks $(-3.8$ headaches/month, $95 \%$ CI: -5.4 to -2.3$)$, and 24 weeks ( -5.0 headaches/month, $95 \% \mathrm{CI}:-7.9$ to -2.1 ).

Secondary outcomes are given in Online Table 2. Patients given amitriptyline consumed fewer analgesic doses and had a reduced headache index at most time points, with the benefit increasing over time. For example, the analgesic dose reduction was 9.2 (95\% CI: -24.6 to 6.1) fewer doses per month at 4 weeks of treatment, and gradually increased to 18 (95\% CI: -28.2 to -7.8 ) fewer doses per month by 24 weeks (Online Figure 2). TCAs were more effective than placebo at improving quality of life, but not in reducing headache severity or duration, and were not more likely to result in at least $50 \%$ improvement in headaches.

Patients on tricyclics were more likely to experience drowsiness (RR: 1.9, 95\% CI: 1.2-2.9) and dry mouth (RR: 2.3,
95\% CI: 1.6-3.3) than those on placebo, but were not more likely to withdraw from the study (RR: 1.6, 95\% CI: 0.78-3.1) or experience other side effects (Online Table 2).

The quality of evidence for the comparison between TCAs and placebo was graded as high. There was no evidence of publication bias for TCA effect on headache frequency (Egger $p=0.74)$, headache index (Egger $p=0.23$ ), or analgesic medication consumption (Egger $p=0.14$ ) at 8 weeks, the most commonly reported time point. There was no evidence of heterogeneity for our primary outcome at 4 or 8 weeks, although there was moderate heterogeneity at 12 weeks. There was no relationship between sample size $(p=0.79)$, age $(p=0.62)$, gender $(p=0.43)$, TCA dose $(p=0.68)$, quality $(p=0.07)$, dropouts $(p=0.14)$, or inclusion of depressed patients $(p=0.17)$ and our primary outcome.

\section{Tetracyclic versus Placebo}

Two blinded randomized trials compared two different tetracyclics, mirtazapine ${ }^{34}$ and mianserin, ${ }^{51}$ to placebo. There was no difference in the efficacy of tetracyclics on chronic tension-type headaches compared to placebo on any outcome measured, though most outcomes were only reported by a single trial (Online Table 2). We graded the quality of evidence for this comparison as low. There was insufficient data to assess for publication bias.

\section{Comparative Effectiveness Trials}

There were 15 randomized studies that compared at least two active modalities ${ }^{33-36,38,42,43,47,48,51,52,54,56,59,62,63}$ (Online Table 1). All included amitriptyline as one of the comparison groups. TCAs were compared to SSRIs in four studies. $33,38,59,62$ Amitriptyline was also compared to a combination of amitriptyline and tizanidine, ${ }^{35}$ the tetracyclic mirtazapine, ${ }^{52}$ buspirone,${ }^{54}$ doxepin, ${ }^{63}$ and amitriptylinoxide. ${ }^{58}$ In addition, amitriptyline was compared to several non-pharmacological modalities. Two studies compared amitriptyline to a combination of stress management and cognitive behavioral therapy (CBT). ${ }^{47,48}$ Single-trial comparisons to amitriptyline included spinal manipulation, ${ }^{36}$ transcutaneous electrical nerve stimulation (TENS) ${ }^{56}$ and courttype traditional Thai massage, ${ }^{42}$ which applies pressure on specific points along the meridian lines using polite gestures, since it was originally used for royal families. All of the studies were limited in that they were not formal equivalence trials. Most were small and of short duration, and most used low doses of tricyclics that were unlikely to have clinical effects against headaches.

\section{TCA versus SSRIs}

Among the five trials comparing TCAs to SSRIs, one had no extractable data, and the authors did not respond to our attempts to obtain data. ${ }^{57}$ Three studies compared amitriptyline to citalopram $^{33,59}$ or sertraline, ${ }^{38}$ and one compared desipramine to fluoxetine. ${ }^{62}$ For our primary outcome, headache frequency, there was no difference between TCAs and SSRIs at 4 weeks (WMD -1.2 headaches/month, 95\% CI: -3.6 to 1.1 ), 8 weeks (WMD -2.1 headaches/month, 95\% CI: -5.1 to 0.92 ), 


\begin{tabular}{|c|c|c|c|c|c|}
\hline & Favors TCA & Favors Placebo & $\begin{array}{l}\text { Headaches/month } \\
(95 \% \mathrm{Cl})\end{array}$ & $\begin{array}{l}\text { TREATMENT } \\
\mathrm{n}, \text { mean, SD }\end{array}$ & $\begin{array}{l}\text { CONTROL } \\
\text { n, mean, SD }\end{array}$ \\
\hline \multicolumn{6}{|l|}{4 weeks } \\
\hline Holroyd 2001 (amitriptyline) & & & $-6.00(-8.55,-3.45)$ & $48,5.5(6)$ & $38,11.5(6)$ \\
\hline Indaco 1988 (amitriptyline) & & & $-6.40(-9.44,-3.36)$ & $15,6.8(3.7)$ & $16,13.2(4.9)$ \\
\hline Subtotal $\left(I^{2}=0.0 \%\right)$ & & & $-6.17(-8.12,-4.21)$ & 63 & 54 \\
\hline \multicolumn{6}{|l|}{8 weeks } \\
\hline Bendtsen 1996 (amitriptyline) & & & $-3.10(-7.14,0.94)$ & $34,18.6(9.33)$ & $34,21.7(7.58)$ \\
\hline Holroyd 2001 (amitriptyline) & & & $-5.40(-8.31,-2.49)$ & $44,6.2(6)$ & $26,11.6(6)$ \\
\hline Indaco 1988 (amitriptyline) & & & $-5.40(-8.59,-2.21)$ & $15,7.1(3.2)$ & $16,12.5(5.6)$ \\
\hline Morland 1979 (doxepin) & & & $-3.18(-10.59,4.23)$ & $14,29.3(10)$ & $14,32.5(10)$ \\
\hline Subtotal $\left(1^{2}=0.0 \%\right)$ & & & $-4.79(-6.63,-2.95)$ & 107 & 90 \\
\hline \multicolumn{6}{|l|}{12 weeks } \\
\hline Holroyd 2001 (amitriptyline) & & & $-5.30(-8.21,-2.39)$ & $44,6.4(6)$ & $26,11.7(6)$ \\
\hline Indaco 1988 (amitriptyline) & & & $-8.60(-11.74,-5.46)$ & $15,5.2(2.4)$ & $16,13.8(5.9)$ \\
\hline Pfaffenrath 1994 (amitriptylinoxide) & & & $0.00(-3.09,3.09)$ & $66,16(9)$ & $64,16(9)$ \\
\hline Pfaffenrath 1994 (amitriptyline) & & & $-1.00(-4.26,2.26)$ & $67,15(10)$ & $64,16(9)$ \\
\hline Subtotal $\left(I^{2}=83.9 \%\right)$ & & & $-3.81(-5.36,-2.26)$ & 192 & 170 \\
\hline \multicolumn{6}{|l|}{24 weeks } \\
\hline Holroyd 2001 (amitriptyline) & $\rightarrow$ & & $-5.00(-7.91,-2.09)$ & $44,7(6)$ & $26,12(6)$ \\
\hline $\begin{array}{l} \\
-11.7\end{array}$ & & & $\begin{array}{l}7 \\
11.7\end{array}$ & & \\
\hline
\end{tabular}

Figure 1 Headaches per month, TCA vs. placebo.

or 12 weeks (WMD: $-0.8,95 \%$ CI: 02.9 to 1.3 ; Fig. 2), though by 16 weeks TCAs were superior to SSRIs (WMD -4.5 headaches/month, 95\% CI: -6.3 to -2.7 ). This is similar to the impact on headache index, with no difference at 4 weeks (SMD -0.32 , 95\% CI: -0.76 to 0.10 ), but with evidence for the superiority of amitriptyline at 8 weeks (SMD $-0.42,95 \%$ CI: -0.85 to -0.001 ) and 12 weeks (SMD $-0.52,95 \%$ CI: -0.95 to -0.08 ).

Similarly, there was no difference in analgesic consumption at 4 weeks (WMD: -0.11 doses/month, $95 \%$ CI: -4.3 to 4.1 ; Online Table 2), though tricyclics were more effective at reducing analgesic use at 8 weeks (WMD: -4.8 doses/month, 95\% CI: -8.4 to -1.3 ) and 12 weeks (WMD: -5.2 doses/month, 95\% CI: -9.1 to -1.3 ). There was no difference between TCAs and SSRIs in headache severity at any time point reported (Online Table 2). The difference in headache duration was inconsistent, with no difference at 4 weeks (WMD: $-0.60 \mathrm{~h}, 95 \% \mathrm{CI}:-2.3$ to 1.1 ) or 12 weeks (WMD $-1.3,95 \%$ CI: -3.0 to 0.39 ), though TCAs were superior to SSRIs at 8 weeks (WMD $-1.3,95 \% \mathrm{CI}$ : -2.5 to $-0.08)$.

Tricyclics were not more likely to cause drowsiness, dry mouth, or "other" side effects (Online Table 2) than SSRIs. Subjects receiving tricyclics were not more likely to withdraw from the study than those receiving SSRIs. We graded the comparison of TCAs to SSRIs to be of moderate quality. There were insufficient numbers of trials at any time point to assess for publication bias.

\section{Other Comparative Effectiveness Trials}

Other comparisons that were limited to one or two trials generally had few outcomes reported and often used very low doses of TCAs. Full results are given in Online Table 2. Two trials compared amitriptyline to two other TCAs (amitriptylinoxide ${ }^{41}$ and doxepin ${ }^{43}$ ), finding no differences in outcomes. Two trials compared TCAs to tetracyclics, also finding no differences. In a single study, amitriptyline was more effective than buspirone. Single trials found no difference between the combination of amitriptyline and tizanidine, spinal manipulation, intra-oral orthotics, TENS units, or court-style traditional Thai-massage. Generally, these trials used doses of amitriptyline that were too low to be effective (chiropractic: $25 \mathrm{mg}$, orthotics: $10 \mathrm{mg}$, TENS: $50 \mathrm{mg}$, massage: $25 \mathrm{mg}$ ). Two trials found that the effect of fulldose amitriptyline was no different from that of a combination of stress management and CBT. Mirtazapine was compared to 


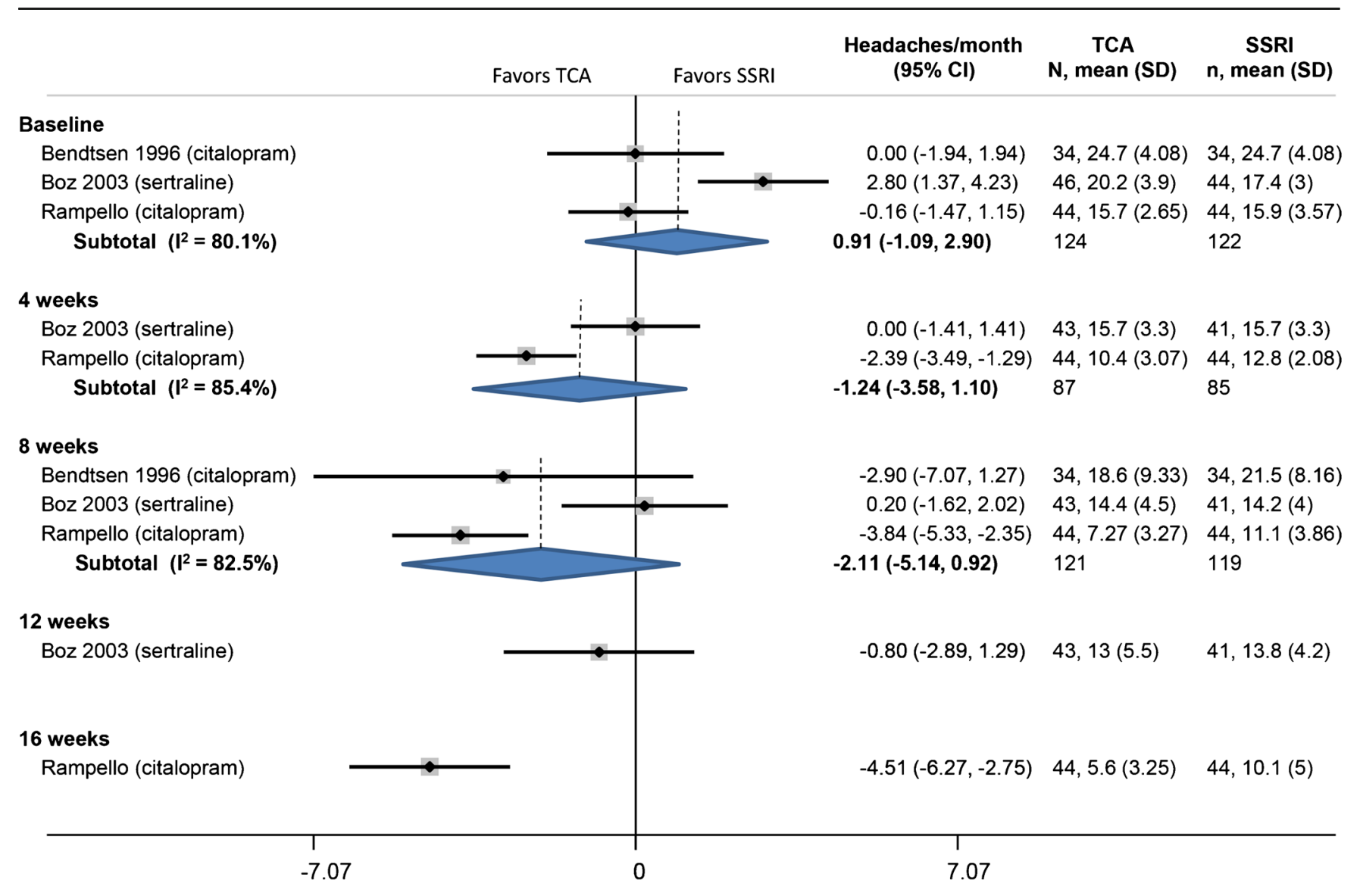

\section{Reduction in headaches/month}

Figure 2 Headaches per month, TCA vs. SSRIs.

ibuprofen and the combination of mirtazapine and ibuprofen, with no difference in any outcomes measured. The quality of evidence for all of these comparisons was rated low.

\section{DISCUSSION}

We found that TCAs are more effective than placebo in managing chronic tension-type headache, reducing headache frequency by about seven headaches per month (from 17 to 10). This reduction could be seen as early as 1 month after initiation of treatment, though it appeared to be more effective over time. Patients given TCAs can also expect to take fewer doses of analgesics, about 16-18 doses per month. This degree of improvement is less than the effect of TCAs in the prophylaxis of chronic migraine headache ${ }^{21}$ and is less than previously reported in our systematic review. ${ }^{21}$ This degree of reduction is less than $50 \%$ of the baseline headache frequency. Providers and patients will need to discuss whether the side effects common to TCAs are worth this degree of headache reduction. Few studies were more than 12 weeks in duration, so it is unknown whether any benefit persists over time. The optimum dose is also uncertain; most placebo trials used doses of amitriptyline ranging from 50 to $150 \mathrm{mg}$. Tetracyclics were ineffective in treating tension-type headaches, though the literature is weak.
In our network meta-analysis, we found that TCAs were more effective than other commonly used treatments for migraine headache; ${ }^{12}$ unfortunately, there are very few studies using other modalities for tension-type headache. Moderatequality evidence suggests that TCAs are better than SSRIs. There is low-quality evidence that TCAs are better than buspirone. Other comparisons with pharmacological and non-pharmacological modalities were all small studies that had a number of important methodological problems, rendering definitive conclusions impossible. One common finding was that the comparative TCA groups were given low doses of TCAs, as low as $10 \mathrm{mg}$. Such low doses of TCAs are generally considered inadequate for treating headaches. In a single trial, behavioral therapy was better than placebo, and combining it with TCA produced greater benefit than either alone. ${ }^{47}$

Distinguishing migraine from tension-type headache is not always easy for clinicians. One study evaluated 1203 headache sufferers presenting to primary care and found that $94 \%$ of patients diagnosed with non-migraine headache types actually had migraine, though migraine diagnoses were nearly always correct. ${ }^{64}$ Some headache experts suggest that primary care providers should assume that a chronic disabling headache is migrainous. ${ }^{65}$ In our trials, the diagnoses were generally made by headache specialists, making misdiagnosis less 
likely. The benefit of TCAs over placebo is greater for migraine than tension-type headache, so even if the diagnosis is incorrect, TCAs are likely to be beneficial. Although TCAs were effective for tension-type and migraine headache, this is not evidence that the pathophysiology for both types are the same, since TCAs are beneficial in a broad range of pain syndromes. ${ }^{66}$

This review has a number of significant differences from our previous review, though there has only been one additional trial. ${ }^{42}$ First, we more carefully delineated the time points at which outcomes occurred in this version. Second, in the previous version, we presented results as standardized mean differences, making the results less clinically meaningful. In this review, our primary outcome was headache frequency per month, an outcome that is easily understood by clinicians and patients. The previous review overstated the benefit of TCAs for chronic tension-type headache; the current data provides better information to help inform provider and patient conversations about managing chronic tension-type headache with TCAs. In addition, this review includes information about tetracyclic use in tension-type headache.

Our review has several significant limitations. First, while the quality of evidence for the comparison between TCAs and placebo was graded as high, the other comparisons were generally low-quality, consisting mostly of underpowered single randomized trials. Second, nearly all trials were of amitriptyline. While the limited data from other TCAs (clomipramine, desipramine, doxepin, and imipramine) appeared to show similar effects, one should be cautious in assuming a class effect. Third, studies were inconsistent in reporting outcomes, so even when more than one trial was available, specific outcomes and time points were often limited to a single study. Moreover, there were significant problems with selective reporting of outcomes, and many studies did not collect information on headache frequency, the measure preferred by the IHS. Fourth, the small number of studies available precluded sensitivity analyses, such as assessing for publication bias or fully exploring sources of heterogeneity. For example, depression is commonly comorbid among patients with headaches, yet we were unable to explore the relationship between depression and outcome. Six of the studies reported on the association between depression and headaches, four found no correlation between depression and headache improvement, ${ }^{34,43,49,58}$ and two found a weak correlation. ${ }^{52,62}$ Fifth, we also had an insufficient number of studies to explore whether some TCAs are better tolerated or whether some doses are more effective than others. It is generally well accepted, for example, that nortriptyline is better tolerated and likely to be as effective as amitriptyline. Sixth, nearly all subjects in this analysis met criteria for chronic tension-type headache, experiencing more than 15 headaches per month. How well TCAs will work against frequent episodic tension-type headache is unclear. Seventh, this study suggests that TCAs are more effective over time. However, this could be a confounded association. There were considerable losses to followup, mostly for lack of benefit rather than intolerable side effects.
Since longer-duration trials had greater losses over time, and few trials included an intention-to-treat analysis, it is likely that those who stayed in the trial experienced a benefit while those who dropped out did not, giving the impression that the drug was more effective over time. Finally, one of the most common long-term adverse effect of TCAs is weight gain. While our studies found no evidence of weight gain, the duration of included studies was too short to meaningfully assess for this side effect. Thus, practicing clinicians should be cautious in using our results to shape decisions regarding prophylactic management of chronic tension-type headache.

\section{CONCLUSIONS}

TCAs are effective in reducing the headache burden of patients with chronic tension-type headaches, lowering the number of headaches by 5-6 per month. This would represent considerable residual headache burden, given that subjects in our study averaged 16 headaches per month at baseline. Tricyclics also reduced the number of acute analgesic medications taken per month and improved both the headache index and quality of life. These improvements are modest and need to be weighed against the potential side effects patients may experience.

TCAs are superior to SSRIs, based on several trials. Though evidence is limited to only single trials, TCAs are probably better than buspirone and TENS. Tetracyclics appear to be ineffective in treating chronic tension-type headache; however, the studies were low in number and underpowered. Nonpharmacological comparisons included a behavioral intervention (comprising a combination of stress management and CBT), spinal manipulation, intra-oral orthotics, and massage; all appeared to be comparable to TCAs, though these were all small, low-quality studies, making definitive conclusions highly suspect. While the current study provides evidence of TCA effectiveness in reducing the frequency of chronic tension-type headaches, additional research is needed to strengthen the comparison of TCAs to alternative pharmacological and non-pharmacological treatments.

Acknowledgements: All authors contributed to study conception, the selection of articles for inclusion, the abstraction of the data and assessment of quality, and manuscript preparation or revision. Dr. Jackson conducted the statistical analyses.

Corresponding Author: Jeffrey L. Jackson, MD, MPH; Zablocki VA Medical Center, Milwaukee, WI, USA (e-mail: jjackson@mcw.edu).

\section{Compliance with Ethical Standards:}

Conflict of Interest: The authors declare that they have no conflict of interest.

Funding: No funding was received for this project.

\section{REFERENCES}

1. Stovner LJ, Hagen $\mathbf{K}$, Jensen $\mathbf{J}$, Katsarava Z, Lipton RB, Scher AI et al. The global burden of headache: a documentation of headache prevalence and disability worldwide. Cephalalgia. 2007; 27(3):193-210. 
2. Ferrante T, Manzoni GC, Russo M, Camarda C, Taga A, Veronesi $\mathbf{L}$ et al. Prevalence of tension-type headache in adult general population: the PACE study and review of the literature. Neurol Sci. 2013; 34 Suppl $1:$ S137-S138

3. Lyngberg AC, Rasmussen BK, Jorgensen T, Jensen R. Has the prevalence of migraine and tension-type headache changed over a 12 year period? Eur J Epidemiol. 2005; 20(3):243-249.

4. Rasmussen BK, Jensen R, Schroll M, Olesen J. Epidemiology of headache in a general population-A prevalence study. J Clin Epidemiol. 1991; 44(11):1147-1157.

5. Schwartz BS, Stewart WF, Simon D, Lipton RB. Epidemiology of tension-type headache. JAMA. 1998; 279(5):381-383.

6. Abu Bakar N, Tanprawate S, Lambru G, Torkamani M, Jahanshahi M, Matharu M. Quality of life in primary headache disorders: A review. Cephalalgia. 2016; 36(1):67-91.

7. Rasmussen BK. Epidemiology of headache. Cephalalgia. 2001; 21(7):774-777.

8. Rasmussen BK, Jensen R, Olesen J. Impact of headache on sickness absence and utilisation of medical services: a Danish population study. J Epidemiol Community Health. 1992; 46(4):443-446.

9. Linde M, Gustavsson A, Stovner LJ, Steiner TJ, Barr AJ, Katsarava Z et al. The cost of headache disorders in Europe: the Eurolight project. Eur J Neurol. 2012; 19(5):703-711.

10. Latinovic $\mathbf{R}$, Gulliford $\mathbf{M}$, Ridsdale $\mathbf{L}$. Headache and migraine in primary care: consultation, prescription, and referral rates in a large population. J Neurol Neurosurg Psychiatry. 2006; 77(3):385-387.

11. International Headache S. The International Classification of Headache Disorders, 3rd edition (beta version). Cephalalgia. 2013; 33(9):629-808.

12. Jackson JL, Cogbill E, Santana-Davila R, Eldredge C, Collier W, Gradall A et al. A comparative effectiveness meta-analysis of drugs for the prophylaxis of migraine headaches. PLoS One. 2015; 10(7):e0130733.

13. Becker WJ, Findlay T, Moga C, Scott NA, Harstall C, Taenzer $\mathbf{P}$ Guildeine for primary care management of headache in adults. Can Fam Physician. 2015; 61(8):670-679.

14. Devine JW, Farley JF, Hadsall RS. Patterns and predictors of prescription medication use in the management of headache: findings from the 2000 Medical Expenditure Panel Survey. Headache. 2005; 45(9):11711180 .

15. Mafi JN, Edwards ST, Pedersen NP, Davis RB, McCarthy EP, Landon BE. Trends in the ambulatory management of headache: analysis of NAMCS and NHAMCS data 1999-2010. J Gen Intern Med. 2015; 30(5):548-555

16. Langer-Gould AM, Anderson WE, Armstrong MJ, Cohen AB, Eccher MA, Iverson DJ et al. The American Academy of Neurology's top five choosing wisely recommendations. Neurology. 2013; 81(11):1004-1011.

17. Linde $\mathbf{K}$, Allais G, Brinkhaus B, Fei Y, Mehring M, Shin BC et al Acupuncture for the prevention of tension-type headache. Cochrane Database Syst Rev. 2016; 4:CD007587.

18. Banzi R, Cusi C, Randazzo C, Sterzi R, Tedesco D, Moja L. Selective serotonin reuptake inhibitors (SSRIs) and serotonin-norepinephrine reuptake inhibitors (SNRIs) for the prevention of tension-type headache in adults. Cochrane Database Syst Rev. 2015;(5):CD011681.

19. Jackson JL, Kuriyama A, Hayashino Y. Botulinum toxin A for prophylactic treatment of migraine and tension headaches in adults: a meta-analysis. JAMA. 2012; 307(16):1736-1745.

20. Fernandez-de-Las-Penas C, Alonso-Blanco C, Cuadrado $\mathbf{M L}$ Miangolarra JC, Barriga FJ, Pareja JA. Are manual therapies effective in reducing pain from tension-type headache?: a systematic review. Clin J Pain. 2006; 22(3):278-285.

21. Jackson JL, Shimeall W, Sessums L, DeZee KJ, Becher D, Diemer M et al. Tricyclic antidepressants and headaches: systematic review and meta-analysis. BMJ. 2010; 341(c5222).

22. Moher D, Liverati A, Tetzlaff J, Altman DG. Preferred reporting items for systematic reviews and meta-analyses: the PRISMA statement. PLOS Med. 2009; 6(7):e1000097.

23. Higgins JPT, Green S. Cochrane Handbook for Systematic Reviews of Interventions Version 5.0.2. www.cochrane-handbook.org. 2011.

24. Jadad AR, Moore RA, Carroll D, Jenkinson C, Reynolds DJ, Gavaghan DJ et al. Assessing the quality of reports of randomized clinical trials: is blinding necessary? Control Clin Trials. 1996; 17(1):1-12.

25. Kroenke K, Jackson JL. Outcome in general medical patients presenting with common symptoms. A prospective study with 2 week and 3 month follow-up. Family Pract. 1998; 15:398-403.

26. Kazis LE, Anderson JJ, Meenan RF. Effect sizes for interpreting changes in health status. Med Care. 1989; 27 Suppl 3:S178-S189.
27. Follmann D, Elliott P, Suh I, Cutler J. Variance imputation for overviews of clinical trials with continuous response. J Clin Epidemiol. 1992; 45(7):769-773.

28. Galbraith RF. A note on graphical presentation of estimated odds ratios from several clinical trials. Stat Med. 1988; 7(8):889-894

29. Higgins JP, Thompson SG, Deeks JJ, Altman DG. Measuring inconsistency in meta-analyses. BMJ. 2003; 327(7414):557-560.

30. Peters JL, Sutton AJ, Jones DR, Abrams KR, Rushton L. Comparison of two methods to detect publication bias in meta-analysis. JAMA. 2006; 295(6):676-680.

31. Egger M, Davey Smith G, Schneider M, Minder C. Bias in meta-analysis detected by a simple, graphical test. BMJ. 1997; 315(7109):629-634.

32. GRADEpro Guideline Development Tool [Software]. McMaster University (developed by Evidence Prime, Inc.); 2015.

33. Bendtsen $\mathbf{L}$, Jensen R, Olesen J. A non-selective (amitriptyline), but not a selective (citalopram), serotonin reuptake inhibitor is effective in the prophylactic treatment of chronic tension-type headache. J Neurol Neurosurg Psychiatry. 1996; 61(3):285-290.

34. Bendtsen L, Buchgreitz L, Ashina S, Jensen R. Combination of lowdose mirtazapine and ibuprofen for prophylaxis of chronic tension-type headache. Eur J Neurol. 2007; 14(1468-1331 (Electronic), 1351-5101 (Linking), 2):187-193.

35. Bettucci D, Testa L, Calzoni S, Mantegazza P, Viana M, Monaco F. Combination of tizanidine and amitriptyline in the prophylaxis of chronic tension-type headache: evaluation of efficacy and impact on quality of life. J Headache Pain. 2006; 7(1):34-36.

36. Boline PD, Kassak K, Bronfort G, Nelson C, Anderson AV. Spinal manipulation vs. amitriptyline for the treatment of chronic tension-type headaches: a randomized clinical trial. J Manip Physiol Ther. 1995; 18(3): 148-154.

37. Bonuso S, Di Stasio E, Barone P, Steardo L. Timed-release dihydroergotamine in the prophylaxis of mixed headache. A study versus amitriptyline. Cephalalgia. 1983; 3 Suppl 1:175-178.

38. Boz C, Altunayoglu V, Velioglu S, Ozmenoglu M. Sertraline versus amitriptyline in the prophylactic therapy of non-depressed chronic tension-type headache patients. J Headache Pain. 2003; 4(2):72-78.

39. Canepari C, Riva M, Erminio F. Effectiveness of flunarizine in chronic headache. Double-blind study of placebo and amitriptyline. Clin Ter. 1985; 115(0009-9074 (Print), 0009-9074 (Linking), 6):463-468.

40. Catarci T, Fabbrini G, Barbanti P, Cerbo R. Amitriptyline in preventive treatment of tension headaches in non-depressed patients is efficient for chronic, but not for episodic cases. Confinia Cephalalgica. 1996; 5(2):43-49.

41. Couch JR, Amitriptyline Versus Placebo Study Group. Amitriptyline in the prophylactic treatment of migraine and chronic daily headache. Headache. 2011; 51(1):33-51.

42. Damapong P, Kanchanakhan N, Eungpinichpong W, Putthapitak P. A randomized controlled trial on the effectiveness of court-type traditional Thai massage versus amitriptyline in patients with chronic tension-type headache. Evid Based Complement Alternat Med. 2015; 2015(930175): 12 .

43. de Tommaso M, Shevel E, Pecoraro C, Sardaro M, Divenere D, Di fruscolo $O$ et al. Intra-oral orthosis vs. amitriptyline in chronic tensiontype headache: a clinical and laser evoked potentials study. Head Face Med. 2006; 2:15.

44. Descombes S, Brefel-Courbon C, Thalamas C, Albucher JF, Rascol O, Montastruc $\mathbf{J L}$ et al. Amitriptyline treatment in chronic drug-induced headache: a double-blind comparative pilot study. Headache. 2001; 41(2): 178-182.

45. Diamond S, Baltes BJ. Chronic tension headache-treated with amitriptyline-a double-blind study. Headache. 1971; 11(3):110-116.

46. Gobel H, Hamouz V, Hansen C, Heininger $\mathbf{K}$, Hirsch S, Lindner V et al. Chronic tension-type headache: amitriptyline reduces clinical headacheduration and experimental pain sensitivity but does not alter pericranial muscle activity readings. Pain. 1994; 59(2):241-249.

47. Holroyd KA, Nash JM, Pingel JD, Cordingley GE, Jerome A. A comparison of pharmacological (amitriptyline HCL) and nonpharmacological (cognitive-behavioral) therapies for chronic tension headaches. J Consult Clin Psychol. 1991; 59(3):387-393.

48. Holroyd KA, O'Donnell FJ, Stenland M, Lipchik GL, Cordingley GE, Carlson BW. Management of chronic tension-type headache with tricyclic antidepressant medication, stress management therapy, and their combination - A randomized controlled trial. JAMA. 2001; 285(17):2208-2215

49. Indaco A, Carrieri PB. Amitriptyline in the treatment of headache in patients with Parkinson's disease: a double-blind placebo-controlled study. Neurology. 1988; 38(11):1720-1722. 
50. Krymchantowski AV, Silva MT, Barbosa JS, Alves LA. Amitriptyline versus amitriptyline combined with fluoxetine in the preventative treatment of transformed migraine: a double-blind study. Headache. 2002; 42(6):510-514.

51. Langemark M, Loldrup D, Bech $\mathbf{P}$, Olesen J. Clomipramine and mianserin in the treatment of chronic tension headache. A double-blind, controlled study. Headache. 1990; 30(3):118-121.

52. Martin-Araguz A, Bustamante-Martinez C, de Pedro-Pijoan JM. Treatment of chronic tension-type headache with mirtazapine and amitriptyline. Revista De Neurologia. 2003; 37(2):101-105.

53. Mathew NT. Prophylaxis of migraine and mixed headache. A randomized controlled study. Headache. 1981; 21(0017-8748 (Print), 0017-8748 (Linking), 3): 105-109.

54. Mitsikostas DD, Gatzonis S, Thomas A, Ilias A. Buspirone vs amitriptyline in the treatment of chronic tension-type headache. Acta Neurol Scand. 1997; 96(4):247-251.

55. Morland TJ, Storli OV, Mogstad TE. Doxepin in the prophylactic treatment of mixed 'vascular' and tension headache. Headache. 1979; 19(7):382-383.

56. Mousavi SA, Mirbod SM, Khorvash F. Comparison between efficacy of imipramine and transcutaneous electrical nerve stimulation in the prophylaxis of chronic tension-type headache: a randomized controlled clinical trial. J Res Med Sci 2011; 16(7):923-927.

57. Oguzhanoglu A, Sahiner T, Kurt T, Akalin O. Use of amitriptyline and fluoxetine in prophylaxis of migraine and tension-type headaches. Cephalalgia. 1999; 19:531-532.

58. Pfaffenrath V, Diener HC, Isler H, Meyer C, Scholz E, Taneri Z et al. Efficacy and tolerability of amitriptylinoxide in the treatment of chronic tension-type headache: a multi-centre controlled study. Cephalalgia. 1994; 14(2):149-155.
59. Rampello L, Alvano A, Chiecho S, Malaguarnera M, Raffaele R, Vecchio I et al. Evaluation of the prophylactic efficacy of amitriptyline and citalopram, alone or in combination, in patients with comorbidity of depression, migraine and tension-type headache. Neuropsychobiology. 2004; 50:322-328

60. Tarasova SV, Amelin AV, Skoromets AA. Fluvoxamine, amitriptyline and transcranial electrostimulation of the brain in the treatment of chronic daily headache. Zh Nevrol Psikhiatr Im S S Korsakova. 2008; 108(6):43-46.

61. Vernon H, Jansz G, Goldsmith $\mathbf{C H}$, McDermaid C. A randomized, placebo-controlled clinical trial of chiropractic and medical prophylactic treatment of adults with tension-type headache: Results from a stopped trial. J Manip Physiol Ther. 2009; 32(5):344-351.

62. Walker Z, Walker RWH, Robertson MM, Stansfeld S. Antidepressant treatment of chronic tension-type headache: A comparison between fluoxetine and desipramine. Headache. 1998; 38(7):523-528.

63. Worz R, Scherhag R. Treatment of chronic tension headache with doxepin or amitriptyline: Results of a double-blind study. Headache $\mathrm{Q}$. 1990; 1(3):216-223.

64. Tepper SJ, Dahlof CG, Dowson A, Newman L, Mansbach H, Jones M et al. Prevalence and diagnosis of migraine in patients consulting their physician with a complaint of headache: data from the Landmark Study. Headache. 2004; 44(9):856-864.

65. Sheftell FD, Tepper SJ. New paradigms in the recognition and acute treatment of migraine. Headache. 2002; 42(1):58-69.

66. O'Malley PG, Jackson JL, Santoro J, Tomkins G, Balden E, Kroenke K. Antidepressant therapy for unexplained symptoms and symptom syndromes. J Fam Pract. 1999; 48(12):980-990. 